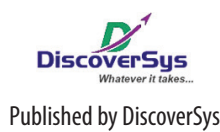

Published by DiscoverSys

\section{Predictors of treatment interruption among tuberculosis patients in public health centres in Bali, Indonesia}

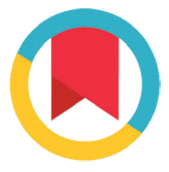

CrossMark

\author{
Putu Ika Farmani, ${ }^{1 *}$ Dewa Nyoman Wirawan, ${ }^{1,2}$ Anak Agung Sagung Sawitri, ${ }^{1,2}$ \\ I Wayan Gede Artawan Eka Putra ${ }^{1,3}$
}

\title{
ABSTRACT
}

Background and purpose: Tuberculosis treatment interruption (TBTI) is one factor that leads to treatment failure, tuberculosis (TB) drug resistance and drop out. The purpose of this study is to identify the incidence and the predictors of TB TI in public health centres (PHCs) in Bali.

Methods: A retrospective longitudinal study was conducted using secondary data of 644 cohorts of TB patients on the first regiment who enrolled in 11 PHCs in Denpasar Bali during 2011-2012. Information from TB program officers in PHCs was also obtained to determine the differences within the practical implementation of TB treatment. Data were analysed using Kaplan Meier and Cox Proportional Hazard Regression.
Results: The study revealed that 378 patients experienced TB TI with the total events of 535. The incidence rate of TB TI event was 5.1 per 1.000 person days and the median time was 56 days (IQR: 56-57). Predictors of the TB TI were male (AHR=1.22; 95\% Cl: 1.021.45; $p=0.027)$ and a more flexible schedule to take the medicine (AHR=1.47; 95\%Cl: 1.22-1.76; $p<0.0001)$.

Conclusions: The implementation of fixed schedule and shortened time lapse for patients to take TB drug will enable more close contact between patients and health providers. Intensive adherence counselling especially tailored for male patients is also required.
${ }^{1}$ Public Health Postgraduate Program Udayana University, ${ }^{2}$ Department of Community and Preventive Medicine Faculty of Medicine Udayana University, ${ }^{3}$ School of Public Health Faculty of Medicine Udayana University University

\section{${ }^{*}$ Correspondence to:}

Putu Ika Farmani, Public Health Postgraduate Program Udayana University

ika_melo@yahoo.com

Keywords: tuberculosis, treatment, retrospective longitudinal study Cite This Article: Farmani, P.I., Wirawan, D.N., Sawitri, A.A.S., Putra, I.W.G.A.E. 2017. Predictors of treatment interruption among tuberculosis patients in public health centres in Bali, Indonesia. Public Health and Preventive Medicine Archive 5(2): 129-134. D0I:10.15562/phpma.v5i2.27

\section{INTRODUCTION}

Tuberculosis (TB) is a major public health problem worldwide and responsible for 9 million morbidities and 1.5 million deaths. ${ }^{1}$ TB treatment is still a major public health issue in Indonesia, wherein TB relapse, multi drug resistance (MDR) and defaulter (where patients do not take drugs for more than 8 weeks), continue to be problematic. In 2012, an estimated proportion of TB relapse cases in Indonesia was $2.4 \%$, while MDR TB was $1.9 \%$ (1.4$2.5)$ in new cases and $12 \%(8.1-17)$ in re-treated cases. $^{2}$ Bali Province accounted for $0.9 \%$ of the total TB cases in Indonesia, ${ }^{3}$ where the highest number of TB cases in 2012 came from Denpasar, the capital city of the province. ${ }^{4}$ All PHCs in Denpasar have implemented the directly observed treatment short course (DOTS) strategy and have trained TB officers related on TB treatment management. However, $11.1 \%$ of TB cases in Denpasar were re-treated, and this accounted for $47 \%$ of suspected MDR-TB cases in Bali. The MDR-TB rate had slightly decreased from $3.9 \%$ in 2012 to $3.7 \%$ in 2013 ; however, the percentage of defaulter of all TB patients had increased from $1.9 \%$ (2012) to $3.7 \%$ (2013). ${ }^{4,5}$

Previous studies showed that patients who did not take medication regularly or experienced treatment interruption (TI) were more likely to be default from treatment, had MDR-TB, and had treatment failure. ${ }^{6-8}$ Several studies in Indonesia have found that among the predictors of $\mathrm{TB}$ TI were relapse status, availability of treatment support, time to initiate TB treatment, home visit, counseling, drug quality, transportation, distance to health facilities, family income, family support, drug side effects, knowledge levels, and health provider's behaviour. ${ }^{9-12}$ Studies in other countries found that gender of the patient (male), ignorance about the time length of TB treatment, distance to health facilities, and smoking were also among the predictors. ${ }^{13-16}$ This study aims to confirm those findings and provide sufficient understanding on the occurrence of TB TI and its predictors, which will provide crucial insight into how to develop better management of TB treatment in the future.

\section{METHODS}

A retrospective longitudinal study was conducted using cohorts of TB patients in eleven PHCs in Denpasar. The study population was TB patients under TB regiment category 1 during 2011-2012. The inclusion criteria were age $\geq 15$ years old and the completion of TB treatment.

Based on the national guideline, ${ }^{17} \mathrm{~TB}$ is diagnosed by sputum and/or radiologic test, and the administration of $\mathrm{TB}$ treatment depends on the 
type of TB (pulmonary or non pulmonary TB) and the history of TB treatment (new or re-treatment). TB treatment Category I consists of two phases: the intensive (two months) and continuation (four months) phase (one month $=28$ days). Sputum is checked after the intensive phase to identify the conversion status of the TB bacilli in the sputum. Those who do not have the conversion must have an insertion phase for one month. In this study we categorized insertion and continuation phase as post intensive phase. TB TI on the intensive phase will delay the start of continuation phase.

Data of predictors extracted from the clinical record were: demographics, clinical condition and programmatic. Demographic data included: age, gender, history of TB treatment (new or referral from other PHCs). Clinical condition included: baseline sputum test result, type of TB infection (pulmonary/non pulmonary), and HIV status. Programmatic factors consisted of: available facilities of the PHC (ability to conduct sputum test including microscopic referral and satellite $\mathrm{PHC}$ ), and patient's relationship to treatment observer (family/not family/N/A). We also interviewed $11 \mathrm{~TB}$ program officers regarding the maximum duration of providing TB drugs to the patient for each visit. We categorized the duration to be: less flexible if the drugs provided maximum of 1 week, and more flexible if the drugs provided up to 2 weeks. Other information gathered in the interview was the common reasons of TB $\mathrm{TI}$, and the strategies implemented by the TB officer to overcome problems related to TB TI.

During the intensive phase, TB TI was defined as the date when patients did not pick up the drug for at least one day to a maximum of 8 weeks. During the continuation phase, TB TI was defined as the date when patients did not pick up the drug for at least 2 consecutive days to a maximum of 8 weeks. In further analysis, we expanded the TB TI definition using interruption for at least 7 consecutive days.

Based on the above definition of TB TI, we used three scenarios to define the events. The first scenario is the first TB TI as an event, the second scenario is the multiple repeated TIs occurred for each patient during the period of observation, and the third scenario is the expanded TB TI definition (7 days). First, we calculated the cumulative incidence of TB TI based on two definitions of events. For further longitudinal analysis, in the first scenario we calculated incidence rate and its median time using survival analysis and Kaplan Meier graph. For the second and third scenario, we calculated the incidence rate and the predictors of TB TI. Cox Regression was used to unearth the hazard ratio (HR), 95\% CI and the $\mathrm{p}$ value. TB patients who experienced default, transferred out, died, and those who did not experience TB TI during the study were censored. Multivariate Cox regression modelling was conducted for all variables with the $p$ value $<0.20$ in the univariate analysis. Analysis was conducted using STATA 12.0.

This research has been approved by the Head of Health District Office of Denpasar, Bali and the Ethics Committee of the Faculty of Medicine, University of Udayana/Sanglah General Hospital.

\section{RESULTS}

A total of 819 TB patients were registered in TB treatment in PHCs in Denpasar between 2011 and 2012. Among those, 175 (21.4\%) medical records were ineligible due to massive incomplete data (6.8\%), <15 years old (6.3\%), and were on the second category of TB treatment $(8.2 \%)$; resulting in $644(78.6 \%)$ medical records that were eligible for the analysis.

Table 1 describes the patients' characteristics. A total of $366(56.8 \%)$ were male with median age 35 years (IQR: 27-48). Almost all (94.7\%) were new TB patients, had pulmonary TB $(91.8 \%)$, were diagnosed based on sputum tests (65.2\%). More than half (68.2\%) were not tested for HIV, and almost all $(94.7 \%)$ had a family member as a treatment observer.

During the 6-8 months of TB treatment, more than half (58.7\%) patients experienced at least one or more episodes of TB TI, leaving 234 (36.3\%) patients who did not experience any TB TI, 10 (1.6\%) defaulted, 14 (2.2\%) died, and 25 (3.9\%) were transferred out. Overall, there were $535(83.1 \%)$ episodes of TB TI, wherein $10.1 \%$ experienced TB TI at $\geq 7$ consecutive days. Longitudinal analysis for the first scenario resulted in the incidence of the first TB TI at 6.1 per 1,000 person days with the median time of 59 days (IQR was not reached), while for the second scenario, the incidence rate of overall incidence of TB TI was 5.1 per 1,000 person days with median time of 61 days (IQR: 56-215). The Kaplan Meier graph indicated that most of the first TB TI occurred within the transition between the intensive and post intensive phase (day $56^{\text {th }}-58^{\text {th }}$ ).

Table 2 describes that variables of gender and sputum test results before TB treatment showed a tendency to be significant for both scenarios, but not for the variable of maximum duration to drug pick up. However, final multivariate model (Table 3) shows a different result. Incidence of TB TI with repeated event were more likely to be among males compared with females (AHR $=1.22$; 95\%CI: 1.02$1.45 ; \mathrm{p}=0.027$ ) and among patients with more flexible duration to take TB drugs (AHR $=1.47 ; 95 \% \mathrm{CI}$ : 1.22-1.76; $\mathrm{p}<0.0001$ ). While TB TI for $\geq 7$ consecutive days was more likely encountered among those who did not have a sputum test $(\mathrm{AHR}=4.79$; 95\%CI:1.09-21.08; $\mathrm{p}=0.04$ ).

Based on the interviews with TB officers, eight of them were less flexible in providing TB drugs 


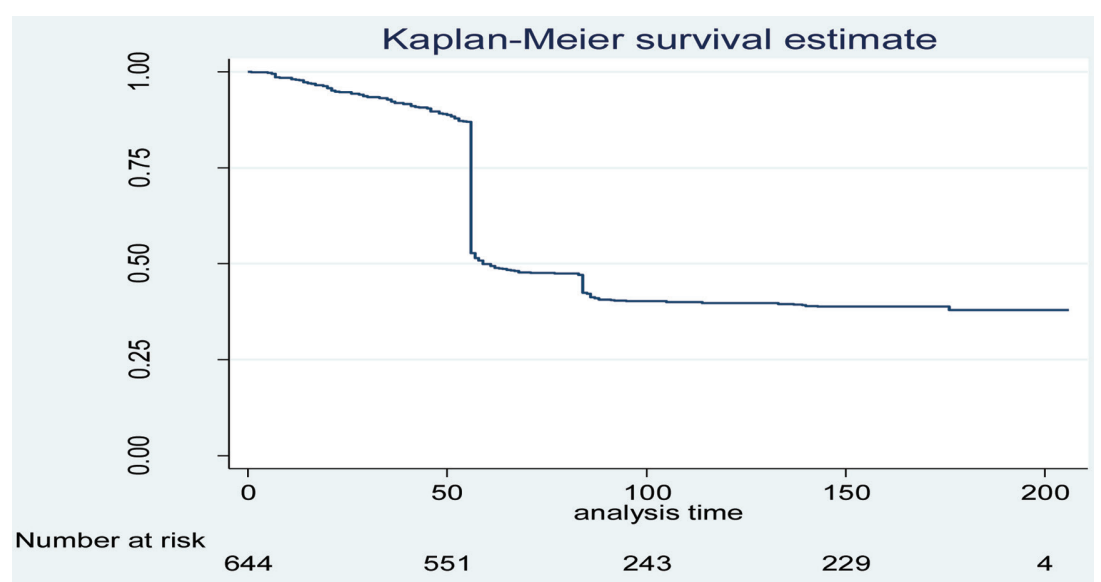

Figure 1 Kaplan Meier of the first of TB treatment interruption

Table 1 Demographics, clinical and programmatics characteristics

\begin{tabular}{|c|c|}
\hline Characteristic & n (\%) \\
\hline \multicolumn{2}{|l|}{ Demographic factors } \\
\hline Age: Median (IQR) & $35(27-48)$ \\
\hline \multicolumn{2}{|l|}{ Gender } \\
\hline Female & $278(43.2)$ \\
\hline Male & $366(56.8)$ \\
\hline \multicolumn{2}{|l|}{ History of TB treatment } \\
\hline New & $610(94.7)$ \\
\hline Referred in & $34(5.3)$ \\
\hline \multicolumn{2}{|l|}{ Clinical condition } \\
\hline \multicolumn{2}{|c|}{ Sputum result test before treatment } \\
\hline Negative & $216(33.5)$ \\
\hline Positive & $420(65.2)$ \\
\hline Not done & $8(1.2)$ \\
\hline \multicolumn{2}{|l|}{ Type of TB infection } \\
\hline Extra pulmonary & $53(8.2)$ \\
\hline Pulmonary & $591(91.8)$ \\
\hline \multicolumn{2}{|l|}{ HIV status } \\
\hline Negative & $197(30.6)$ \\
\hline Positive & $8(1.2)$ \\
\hline Unknown & $439(68.2)$ \\
\hline \multicolumn{2}{|l|}{ Programmatic factor } \\
\hline \multicolumn{2}{|c|}{ Patients relationship to treatment observer } \\
\hline Family & $610(94.7)$ \\
\hline Family and health workers & $1(0.2)$ \\
\hline Health workers & $16(2.5)$ \\
\hline Others & $9(1.4)$ \\
\hline None & $8(1.2)$ \\
\hline
\end{tabular}

${ }^{\star}$ History of TB treatment was categorized into new patients and patients who referred into PHCs

for only one week, while the others were more flexible by giving drugs for more than two weeks on the intensive phase. They stated that the sputum collection was often not timely done, impacted upon the speed of sputum test result dissemination. In providing a response to this, 4 officers admitted that they continued to give the drugs that was used on intensive phase, 3 officers continued to give the drug that was used in the continuation phase, and 3 officers stopped the treatment until they get sputum test result. Only one TB officer had never experienced the late sputum test result.

\section{DISCUSSION}

We found that the overall occurrence of TB TI in Bali in 2011-2012 was relatively high, and mostly occurred in the transition between intensive and post intensive phases. The independent predictors of the occurrence of multiple TB TI were male and patients who had more flexible duration to access medication; while the predictor for TB TI $\geq 7$ consecutive days were patients who were not diagnosed as TB based on sputum test.

Using the first and multiple TB TI definitions, more than half the patients experienced TB TI with the incidence rate of 6.1 and 5.1 per 1,000 person years. As this is the first published study which calculates the incidence of TB TI in Asia, limited data is available to compare this number to other similar studies in Indonesia/Asia. A longitudinal study in Kenya detailed lower cumulative incidence of TB TI among the new patients (4.5\%), but higher among the retreatment patients $(8.5 \%)$, however this study used a different definition of TB TI as when treatment was interrupted for two consecutive months or more. ${ }^{18}$ Many studies in Indonesia measured the proportion of TB TI with cross-sectional studys and put forward a variety of definitions. Our study found that the cumulative incidence of TB TI was $58.7 \%$, while studies in Indonesia ranged from $39.2 \%$ to $86.9 \%{ }^{12,11,19}$ Compared to studies conducted in other countries, the TB TI with TI definition was missed treatment for 2 consecutive days in the intensive phase of treatment, 14 consecutive days in continuation phase (category 1) in Nigeria, for instance,was lower (19\%) than our study. ${ }^{13}$ Despite of TB TI definition, this study supports the fact that occurrences of TB TI in many places in Indonesia were common.

Our study found that most TB TI occurred on day 56, with a median time of the first TB TI and multiple TB TI on day 59 and on the $61^{\text {th }}$. The $56^{\text {th }}$ day should be the end of the intensive phase if patients took medication regularly and without any interruption. This finding paralleled with a retrospective cohort study regarding the drop out of TB patients in South Sumatra, Indonesia, ${ }^{20}$ and retrospective cohort study in India. ${ }^{21}$ Our interviews with TB staff revealed that TB TI during the transition period was due to the slow dissemination of sputum 
Table 2 Univariate analysis of predictors of TB treatment interruption

\begin{tabular}{|c|c|c|c|c|c|c|c|c|}
\hline \multirow[b]{2}{*}{ Variables } & \multicolumn{4}{|c|}{ Multiple (TB TI $\geq 1$ days) } & \multicolumn{4}{|c|}{ TB $\mathrm{TI} \geq 7$ days } \\
\hline & HR & $95 \% \mathrm{Cl}$ & $\mathbf{p}$ & $\mathbf{p}(\mathbf{g})$ & HR & $95 \% \mathrm{Cl}$ & $\mathbf{p}$ & $\mathbf{p}(\mathbf{g})$ \\
\hline \multicolumn{9}{|l|}{ Demographic factor } \\
\hline Age & 1.00 & $0.99-1.00$ & 0.94 & & 1.00 & $0.99-1.02$ & 0.58 & \\
\hline \multicolumn{9}{|l|}{ Gender } \\
\hline Female & 1 (ref) & & & & $1(\mathrm{ref})$ & & & \\
\hline Male & 1.20 & $1.01-1.43$ & 0.04 & & 1.42 & $0.86-2.36$ & 0.18 & \\
\hline \multicolumn{9}{|l|}{ History of TB treatment } \\
\hline New & 1 (ref) & & & & $1(\mathrm{ref})$ & & & \\
\hline Referred in & 0.93 & $0.61-1.39$ & 0.71 & & 1.71 & $0.69-4.25$ & 0.25 & \\
\hline \multicolumn{9}{|l|}{ Clinical condition } \\
\hline \multicolumn{9}{|c|}{ Sputum test result before treatment } \\
\hline Negative & 1 (ref) & & & & $1(\mathrm{ref})$ & & & \\
\hline Positive & 1.22 & $1.01-1.47$ & 0.04 & & 1.82 & $1.01-3.30$ & 0.048 & \\
\hline Not done & 1.65 & $0.81-3.36$ & 0.17 & 0.08 & 4.86 & $1.10-21.40$ & 0.036 & 0.04 \\
\hline \multicolumn{9}{|l|}{ Type of TB infection } \\
\hline Extra pulmonary & 1 (ref) & & & & $1($ ref) & & & \\
\hline Pulmonary & 1.16 & $0.83-1.62$ & 0.38 & & 1.89 & $0.59-6.01$ & 0.28 & \\
\hline \multicolumn{9}{|l|}{ HIV status } \\
\hline Negative & 1 (ref) & & & & 1 (ref) & & & \\
\hline Positive & 1.35 & $0.69-2.64$ & 0.39 & & - & - & - & \\
\hline Not done & 1.06 & $0.88-1.27$ & 0.57 & 0.63 & 1.38 & $0.78-2.42$ & 0.26 & 0.54 \\
\hline \multicolumn{9}{|l|}{ Programmatic factor } \\
\hline \multicolumn{9}{|l|}{ Type of PHC } \\
\hline PHC of microscopic referral & 1 (ref) & & & & 1 (ref) & & & \\
\hline Satellite & 1.10 & $0.90-1.35$ & 0.34 & & 0.96 & $0.54-1.68$ & 0.88 & \\
\hline \multicolumn{9}{|c|}{ Patient's relationship to treatment observer } \\
\hline Family & 1 (ref) & & & & $1(\mathrm{ref})$ & & & \\
\hline Not family & 0.56 & $0.31-0.99$ & 0.045 & & 0.76 & $0.18-3.09$ & 0.70 & \\
\hline None & 1.29 & $0.61-2.72$ & 0.51 & 0.11 & 1.41 & $0.19-10.19$ & 0.73 & 0.87 \\
\hline \multicolumn{9}{|c|}{ The maximum duration to drug pick up } \\
\hline Less flexible & 1 (ref) & & & & $1($ ref $)$ & & & \\
\hline More flexible & 1.46 & $1.21-1.75$ & $<0.0001$ & & 0.88 & $0.49-1.59$ & 0.67 & \\
\hline
\end{tabular}

test results. After two months of taking medication, many patients experienced improved health therefore did not return or were late for follow up sputum check. Phone call or text messages conducted by the TB staff to track and remind patients who were late or to confirm result of sputum test was not always effective. This circumstance resulted in delays in providing TB treatment following the sputum test result. Other studies in Indonesia also found that the lateness of the sputum test result dissemination is one precursor for TB TI. ${ }^{12,19}$ In addition, a study in North Sumatra found that $47.4 \%$ patients with TB TI did not understand the objective of the sputum test and $71.1 \%$ patients commit sputum test not according to the schedule. ${ }^{19}$ In this setting, TB staff's efforts to carry out a home visit were often in vain as sometimes patient could not be found or staff were provided with a falsified address. The efforts of TB staff during this transition phase also played an important role in positively influencing TB TI. When the sputum test result was not available after the intensive phase, PHC staff responded to this situation with different approaches. Some PHC staff chose to continue providing TB treatment, but some other staff decided against this. Patients who were given medication were still in contact with TB staff, therefore there was a lower possibility for treatment interruption compared 
Table 3 Multivariate analysis of predictors of TB treatment interruption

\begin{tabular}{|c|c|c|c|c|c|c|c|}
\hline \multirow[b]{2}{*}{ Variables } & \multicolumn{3}{|c|}{ Multiple (TB TI $\geq 1$ days) } & \multicolumn{3}{|c|}{ TB $\mathrm{TI} \geq 7$ days } & \multirow[b]{2}{*}{$\mathbf{p}(\mathbf{g})$} \\
\hline & AHR & $95 \% \mathrm{Cl}$ & $\mathbf{p}$ & AHR & $95 \% \mathrm{Cl}$ & $\mathbf{p}$ & \\
\hline \multicolumn{8}{|l|}{ Demographic factor } \\
\hline \multicolumn{8}{|l|}{ Gender } \\
\hline Female & 1 (ref) & & & & & & \\
\hline Male & 1.22 & $1.02-1.45$ & 0.027 & & & & \\
\hline \multicolumn{8}{|l|}{ Clinical condition } \\
\hline \multicolumn{8}{|c|}{ Sputum test result before treatment } \\
\hline Negative & & & & 1 (ref) & & & \\
\hline Positive & & & & 1.77 & $0.98-3.22$ & 0.06 & \\
\hline Not done & & & & 4.79 & $1.09-21.08$ & 0.04 & 0.05 \\
\hline \multicolumn{8}{|c|}{ Programmatic factor } \\
\hline \multicolumn{8}{|c|}{ The maximum duration to drug pick up } \\
\hline Less flexible & 1 (ref) & & & & & & \\
\hline More flexible & 1.47 & $1.22-1.76$ & $<0.0001$ & & & & \\
\hline
\end{tabular}

Secondary data: demographic factor, clinical condition, type of PHC, patient relationship to treatment observer;

Primary data: the maximum duration to take drug

with those who were being stopped for the treatment. The government tried to overcome this matter by introducing a new national policy in March 2015. In this policy, PHC staff are required to continue providing TB treatment regardless of the availability of the sputum test result after the intensive phase. As it is still preliminary, it is too early to identify the effectiveness of this policy to address the issue of TB TI.

In our study, men were more likely to experience TB TI compared with women (AHR=1.22; 95\%CI: $1.02-1.45 ; \mathrm{p}=0.027)$. This is consistent with studies in India, South Africa and Nigeria, and Russia, which discovered that males were more at risk of TB TI compared with females. ${ }^{13-16}$ Another study suggested that this was due to men's lower adherence to DOTS treatment compared with women, ${ }^{22}$ and the tendency of men having a higher risky behaviour such drinking alcohol and smoking. ${ }^{13,15}$ In our study, we did not identify those behaviors, however, this information highlights the importance of possible factors related to men and TB TI, particularly because cigarette smoking was prevalent (29\%) among people with age $\geq 10$ years in Indonesia. 23,24 Another predictor associated with multiple TB TI was the flexibility of schedule for medication provision. This study showed that patients with more flexible schedule for access were less likely to have regular contact with PHC, thus were more likely to experience TB TI. More studies are needed to confirm this association.

For the second scenario (TB TI $\geq 7$ consecutive days), the predictor of TB TI was the patient who did not undergo a sputum test before treatment. There was no previous study that found the relationship between sputum test result before treatment and TB TI, thus there are difficulties in confirming this result. It might also be possible that there was bias in analysis due to the relatively small number of cases in this study.

This study is not without limitations. The definition of multiple TB TI being used in this study (one to 80 days of interruption) might be sensitive to error of recording. In addition, several survival studies which use repeated event analysis were those with recurrent disease outcome and to measure behavior which are relevant with TB TI. ${ }^{25-27}$ Expanded definition of TB TI using 7 consecutive days may therefore provide a more stable measurement of TI. However, our study also found different predictors for each TB TI definition. Using one day and calculating multiple event of TB TI was useful to provide information on the frequency of TB TI which may relate to program implementation. While using 7 consecutive day of TB TI may provide the size of severe TB TI among patients, which may lead to possibility of MDR TB. Our study emphasizes there were a problem in the duration and the frequency of TB TI. Previous studies also associated TB TI with poor outcome of $\mathrm{TB}$ treatment and the occurrence of TB-MDR, ${ }^{28-30}$ however, the definition of TB TI was not exactly same with our TB TI definition.

There are other variables that are evident from other studies to predict the TB TI but not included in this study such as socioeconomic factors (education, occupation, and marital status), distance to health centre, risk behaviour, and other behaviour factors. In addition, as in other studies which use secondary data, incompleteness and error on 
recording data may also be a concern. This study was conducted among TB patients at PHCs which may have different characteristics from those who come from hospital setting.

\section{CONCLUSION}

TB TI are common in Denpasar, in terms of both duration of length TB TI and the frequency. Being men and patients whose pick up the drug more flexible are more likely experienced TB TI. A fixed schedule and shorten interval to take TB medicine allows more contact between patients and health care providers. Adherence counselling for men are needed to reduce TB TI on men patients.

\section{ACKNOWLEDGEMENT}

This study received funding from Australian Aid via Kirby Institute, UNSW Australia on collaboration capacity building program with University of Udayana.

\section{REFERENCES}

1. WHO. Global Tuberculosis Report 2014. France: WHO; 2014.

2. WHO. Indonesia Tuberculosis Profile. Jakarta: WHO; 2015.

3. Ministry of Health of Indonesia. Indonesia Health Profile 2012. Jakarta: Ministry of Health of Indonesia; 2013.

4. Denpasar Health Office. Tuberculosis Program Report 2012. Denpasar: Denpasar Health Office; 2012.

5. Denpasar Health Office. Tuberculosis Program Report 2013. Denpasar: Denpasar Health Office; 2013.

6. Sarwani Dewi DS, Nurlaela S, A IZ. Risk factors of multidrug resistant tuberculosis (MDR-TB). Jurnal Kesehatan Masyarakat. 2012; 8(1): 60-66

7. Jakubowiak W, Bogorodskaya E, Borisov S, Danilova I, Kourbatova E. Treatment interruptions and duration associated with default among new patients with tuberculosis in six regions of Russia. International Journal of Infectious Disease. 2009; 13(3): 362-368.

8. Astuti NK. Regularity relationship sputum conversion patients treated with new cases of pulmonary TB after treatment intensive phase [thesis]. Surakarta: Sebelas Maret University; 2010.

9. Ubaidillah. Factors that influence the treatment irregularity among patient of TB lungs in Lahat, South Sumatra Province: analysis of secondary data [thesis]. Jakarta: University of Indonesia; 2001.

10. Senewe FP. Factors concerning the complience of taking medecine among the lung tuberculosis patients at public health centers, Depok. Buletin Penelitian Kesehatan. 2002; 30(1): $32-38$

11. Raharno T. Related factors of the treatment irregular on patients lungs tuberculosis in Installation Unit BP. Kraton Hospital of Pekalongan [thesis]. Semarang: Diponegoro University; 2005.

12. Simamoro J. Factor affecting the irregularity of patients with tuberculosis getting treatment at the community health centers in Binjai in 2004 [thesis]. Medan: University of Sumatera Utara; 2004.

13. Ibrahim LM, Hadejia IS, Nguku P, et al. Factors associated with interruption of treatment among pulmonary tuberculosis patients in Plateau State, Nigeria. 2011. The Pan Africa Medical Journal. 2014; 17:78.
14. Ahmad SR, Velhal GD. Study of treatment interruption of new sputum smear positive TB cases under DOTS Strategy. International Journal of Medical Science and Public Health. 2014; 3(8)

15. Belilovsky EM, Borisov SE, Cook EF, Shaykevich S, Jakubowiak WM, Kourbatova E V. Treatment Interruptions among patients with tuberculosis in Russian TB Hospitals. International Journal Infectious Disease. 2010; 14(8): 698-703.

16. Connolly C, Davies G, Wilkinson D. Who fails to complete tuberculosis treatment? Temporal trends and risk factors for treatment interruption in a community-based directly observed therapy programme in a rural district of South Africa. Journal Tuberculosis Lung Disease. 1999; 3(12): 1081-1087.

17. Ministry of Health of Indonesia. National Guideline of Tuberculosis Control. Jakarta: Ministry of Health of Indonesia; 2011.

18. Masini EO, Mansour O, Speer CE, et al. Using survival analysis to identify risk factors for treatment interruption among new and retreatment tuberculosis patients in Kenya. PLoS One. 2016: 1-19.

19. Zuliana I. The effect of individual characteristic, health services factor, and treatment support of the patients TB compliance in work area of Pekan Labuhan's Public Health Centre in Medan on 2009 [thesis]. Medan: University of Sumatera Utara ; 2010.

20. Rahmansyah A. The factors that associated to drop out of pulmonary TB cases at Palembang Lung Hospital 2010 [thesis]. Depok: University of Indonesia; 2012.

21. Gupta S, Behera D. Reasons for interruption of anti-tubercular treatment as reported by patients with tuberculosis admitted in a tertiary care institute. Indian Journal of Tuberculosis. 2011; 58(1): 11-17.

22. Wu P-S, Chou P, Chang N-T, Sun W-J, Kuo H-S. Assessment of changes in knowledge and stigmatization following tuberculosis training workshop in Taiwan. Elsevier Formos Med Assoc. 2009; 108(5): 377-385.

23. Ministry of Health of Indonesia. National Basic Health Research. Jakarta: Ministry of Health of Indonesia; 2008.

24. Ministry of Health of Indonesia. Natioal Basic Health Research. Jakarta: Ministry of Health of Indonesia; 2013.

25. Kleinbaum DG, Klein M. Survival analysis : a self-learning text. Secod Edit. (Gail M, Krickeberg K, Samet J, Tsiatis A, Wong W, eds.). USA: Springer; 2005.

26. Sagara I, Giorgi R, Doumbo OK, Piarroux R, Gaudart J. Modelling recurrent events: comparison of statistical models with continuous and discontinuous risk intervals on recurrent malaria episodes data. Malaria Journal. 2014; 13(1): 293.

27. Chen C-Y, Yeh H-H, Huang N, Lin Y-C. Socioeconomic and clinical characteristics associated with repeat suicide attempts among young people. Journal of Adolescent Health. 2014; 54(5): 550-557.

28. Hirpa S, Medhin G, Girma B, Melese M, Mekonen A, Suarez P. Determinants of multidrug-resistant tuberculosis in patients who underwent first-line treatment in Addis Ababa : a case control study. BMC Public Health. 2013; 13(1): 1 .

29. Barroso EC, Mota RMS, Santos RO, Sousa ALO, Barroso JB, Rodrigues JLN. Risk factors for acquired multidrug-resistant tuberculosis. Journal de Pneumologia. 2003; 29(2).

30. Podewils LJ, Gler MTS, Quelapio MI, Chen MP. Patterns of treatment interruption among patients with multidrug-resistant TB (MDR TB) and association with interim and final treatment outcomes. PLoS One. 2013; 8(7): e70064.

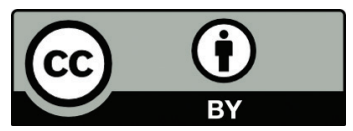

This work is licensed under a Creative Commons Attribution 